\title{
Pattern and outcome of chest injuries at Bugando Medical Centre in Northwestern Tanzania
}

\author{
Monafisha K Lema ${ }^{\dagger}$, Phillipo L Chalya ${ }^{*}$, Joseph B Mabula ${ }^{\dagger}$, William Mahalu ${ }^{\dagger}$
}

\begin{abstract}
Background: Chest injuries constitute a continuing challenge to the trauma or general surgeon practicing in developing countries. This study was conducted to outline the etiological spectrum, injury patterns and short term outcome of these injuries in our setting.

Patients and methods: This was a prospective study involving chest injury patients admitted to Bugando Medical Centre over a six-month period from November 2009 to April 2010 inclusive.

Results: A total of 150 chest injury patients were studied. Males outnumbered females by a ratio of 3.8:1. Their ages ranged from 1 to 80 years (mean $=32.17$ years). The majority of patients $(72.7 \%)$ sustained blunt injuries. Road traffic crush was the most common cause of injuries affecting $50.7 \%$ of patients. Chest wall wounds, hemothorax and rib fractures were the most common type of injuries accounting for 30.0\%, 21.3\% and 20.7\% respectively. Associated injuries were noted in 56.0\% of patients and head/neck (33.3\%) and musculoskeletal regions (26.7\%) were commonly affected. The majority of patients (55.3\%) were treated successfully with nonoperative approach. Underwater seal drainage was performed in 39 patients (19.3\%). One patient (0.7\%) underwent thoracotomy due to hemopericardium. Thirty nine patients (26.0\%) had complications of which wound sepsis (14.7\%) and complications of long bone fractures (12.0\%) were the most common complications. The mean LOS was 13.17 days and mortality rate was 3.3\%. Using multivariate logistic regression analysis, associated injuries, the type of injury, trauma scores (ISS, RTS and PTS) were found to be significant predictors of the LOS $(P<0.001)$, whereas mortality was significantly associated with pre-morbid illness, associated injuries, trauma scores (ISS, RTS and PTS), the need for ICU admission and the presence of complications $(P<0.001)$.

Conclusion: Chest injuries resulting from RTCS remain a major public health problem in this part of Tanzania. Urgent preventive measures targeting at reducing the occurrence of RTCS is necessary to reduce the incidence of chest injuries in this region.
\end{abstract}

\section{Background}

Trauma continues to be an enormous public health problem worldwide and it is associated with high morbidity and mortality both in developed and developing countries [1]. Trauma is reported to be the leading cause of death, hospitalization, and long-term disabilities in the first four decades of life.

Globally, $10 \%$ of all trauma admissions result from chest injuries and $25 \%$ of trauma-related deaths are attributable to chest injuries $[2,3]$.

\footnotetext{
* Correspondence: drphillipoleo@yahoo.com

† Contributed equally

Department of Surgery, Weill- Bugando University College of Health Sciences, Mwanza, Tanzania
}

In Tanzania, trauma including chest injuries continues to be one of the leading causes of morbidity among the young and old with an estimated mortality of 40\% [4]. In Bugando Medical Centre, chest trauma has been commonest cause of surgical admission and contributes significantly to high morbidly and mortality [5].

The causes and pattern of chest injuries have been reported in literature to vary from one part of the world to another partly because of variations in infrastructure, civil violence, wars and crime. Road traffic crushes (RTCs) are the commonest cause of chest injuries in civilian practice accounting for up to $70 \%$ in some series $[6,7]$. With increasing use of firearms, arrows and spears the incidence of penetrating chest injuries increased in civil society [8]. They are often associated with other 
extra-thoracic injuries particularly to the abdomen and long bones $[8,9]$.

Studies have shown that most chest injuries can be treated by non-surgical approach with relatively simple methods, such as tube thoracostomy, appropriate analgesics management, and good pulmonary toilet $[10,11]$. The accurate identification of a patient at high risk for major chest injuries is necessary to avoid delays that may lead to significant morbidity and mortality [12]. Aggressive management of the chest trauma along with prompt treatment of associated injuries is essential for optimal patient outcome [13]. The majority of chest injuries are preventable. A clearer understanding of the causes, injury patterns and outcome of these patients is essential for establishment of prevention strategies as well as treatment protocols [14]. Such data is lacking in our environment as there is no local study which has been done.

This study was conducted in our setting to describe our own experience in the management of chest injuries, outlining the etiological spectrum, injury patterns and outcome of chest injuries in our local setting. The study results will provide basis for planning of prevention strategies and establishment of treatment protocols.

\section{Patients and Methods}

\section{Study design and Setting}

This was a prospective study which was conducted at the Accident and Emergency (A\&E) department and surgical wards of Bugando Medical Centre (BMC) over a sixmonth period from November 2009 to April 2010 inclusive. Bugando Medical Centre is a referral, consultancy and teaching hospital for Weil Bugando University College of Health Sciences (WBUCHS) and other paramedics and it is located in Mwanza city in the northwestern part of Tanzania. It is situated along the shore of Lake Victoria and has a bed capacity of 1000. BMC is one of the four largest referral hospitals in the country and serves as a referral centre for tertiary specialist care for a catchment population of approximately 13 million people from Mwanza, Mara, Kagera, Shinyanga, Tabora and Kigoma.

Trauma patients are first seen at the A \& E department where the surgical team does primary and secondary surveys. The surgical team comprising of intern doctors, Registrar [Medical Officers], Resident [Postgraduate student in Surgery] and Surgeon. From the A \& E department these patients are admitted in respective surgical wards after definitive treatment either in operating theatre or at the A \& E department.

\section{Study subjects}

The study population included all chest injury patients of all age groups and both genders admitted to the surgical wards of BMC during the study period. Unconscious patients without next of kin to consent and give information and those who were still in the ward at the end of study period were excluded from the study. Patients who died before complete assessment and those who absconded against medical advice were also excluded. Recruitment of patient to participate in the study was done at the A\&E department after primary and secondary surveys done by the admitting surgical team. Patients were screened for inclusion criteria and those who met the inclusion criteria were offered explanations about the study and requested to consent before being enrolled into the study. The diagnosis of chest injury was made by clinical history, physical examination and abnormal chest radiographs at the accident and emergency department. Chest injuries were considered as both blunt and penetrating affecting the chest wall and the contents of the thorax e.g. pleura, lungs, lower respiratory tract, esophagus, heart and great vessels. All recruited patients were managed according to advanced trauma life support [ATLS].

Associated injuries were managed appropriately according to type of injury. The authors ensured that the study patients were receiving the appropriate treatment and supportive care as prescribed by the surgeon. Patients were followed up till discharge or death. The length of hospital stay and mortality as measures of outcome of chest injury patients was recorded at the end of follow up period. The minimum follow-up period was thirty days. Data was collected using a pre-tested coded questionnaire. Data administered in the questionnaire included; demographic characteristics (e.g. age, sex), circumstances of injury, characteristics of injury causes, management, complications, Length of Hospital Stay (LOS) and mortality.

\section{Data collection and analysis}

Data collected was entered into a computer and analyzed using SPSS software version 11.5 with help of a medical statistician. Data was summarized in form of proportions and frequency tables for categorical variables. Means, median, mode, standard deviation and histograms were used to summarize continuous variables. Chi-square test was used to test for significance of associations between the predictor and outcome variables in the categorical variables. Student t-test was used to test for significance of associations between the predictor and outcome variables in the continuous variables. Multivariate logistic regression analysis was used to determine predictor variables that are associated with outcome. Significance was defined as a $p$-value of less than 0.05 .

\section{Ethical consideration}

Ethical approval to conduct the study was obtained from the WBUCHS/BMC joint institutional ethic review 
committee before the commencement of the study. Informed consent was sought from each patient before recruitment into the study.

\section{Results}

A total number of 150 chest injury patients were studied. Their ages ranged from 1 to 80 years with a mean of 32.17 years and standard deviation of 14.74. The median and the mode were 30.00 and 22.00 years respectively. The peak age incidence was 21-30 years

There were 119 (79.3\%) males and 31 (20.7\%) females with the male to female ratio of 3.8:1 with a male predominance in each age group (Table 1).

Six patients $(4.0 \%)$ presented with history of premorbid. There was significant association between premorbid illness and mortality $(\mathrm{P}=0.047)$ but not LOS $(\mathrm{P}=0.925)$. The majority of patients $(95 ; 63.3 \%)$ were injured during the day. One hundred and ten patients (73.3\%) were attended within 24 hours of the injury. The remaining forty patients $(26.7 \%)$ were attended more than 24 hours since the injury occurred. Timing in seeking medical care did not significantly influence both LOS $(P=0.095)$ and mortality $(P=0.089)$. The majority of patients 109(72.7\%) sustained blunt injuries. The remaining patients had either penetrating injuries in 40 patients $(26.7 \%)$ or combined (blunt and penetrating) injuries in $1(0.6 \%)$. The mechanism of injury was not significantly associated with LOS $(\mathrm{P}>0.05)$ and mortality $(\mathrm{P}>0.05)$. Road traffic accident was the most common cause of injuries affecting 76(50.7\%) of patients (Table 2).

In this study, the cause of injury did not significantly affect the outcome of chest injury patients in terms of either LOS $(P>0.05)$ or mortality $(P>0.05$. Thirty two patients $(21.3 \%)$ received prehospital care. There was statistically significant association between prehospital treatment and either LOS $(\mathrm{P}=0.001)$ and mortality $(P=0.001)$. Chest wall wounds, hemothorax and rib fractures were the most common type of injuries accounting for $30.0 \%, 21.3 \%$ and $20.7 \%$ respectively (Table 3).

Table 1 Age group distribution according to sex

\begin{tabular}{llll}
\hline Age Group & Males & Females & Total \\
\hline $0-10$ & $7(4.6 \%)$ & $5(3.4 \%)$ & $12(8.0 \%)$ \\
$11-20$ & $8(5.3 \%)$ & $4(2.7 \%)$ & $12(8.0 \%)$ \\
$21-30$ & $47(31.3 \%)$ & $7(4.6 \%)$ & $54(36.0 \%)$ \\
$31-40$ & $29(19.3 \%)$ & $9(6.0 \%)$ & $38(25.3 \%)$ \\
$41-50$ & $17(11.3 \%)$ & $2(1.3 \%)$ & $19(12.6 \%)$ \\
$51-60$ & $9(6.0 \%)$ & - & $9(6.0 \%)$ \\
$61-70$ & - & $3(2.0 \%)$ & $3(2.0 \%)$ \\
$71-80$ & $2(1.3 \%)$ & $1(0.7 \%)$ & $3(2.0 \%)$ \\
\hline Total & $\mathbf{1 1 9 ( 7 9 . 3 \% )}$ & $\mathbf{3 1 ( 2 0 . 7 \% )}$ & $\mathbf{1 5 0 ( 1 0 0 \% )}$ \\
\hline
\end{tabular}

Table 2 Distribution of study population according to the cause of injury

\begin{tabular}{lll}
\hline Cause of injury & Number of patients & Percentage \\
\hline Road traffic accident & 76 & 50.7 \\
Assault & 42 & 28.0 \\
Fall & 24 & 16.0 \\
Sport injuries & 2 & 1.3 \\
Others & 6 & 4.0 \\
\hline Total & $\mathbf{1 5 0}$ & $\mathbf{1 0 0}$ \\
\hline
\end{tabular}

The type of injury; (soft tissue thoracic trauma, rib fractures, hemothorax) significantly influenced the LOS $(\mathrm{P}<0.05)$ but not mortality $(\mathrm{P}>0.05)$. Associated extra-thoracic injuries were noted in $56.0 \%$ of patients and head/neck (33.3\%) and musculoskeletal regions (26.7\%) were commonly affected (Table 4).

The mean Injury severity score (ISS), Revised trauma score (RTS) and Pediatric trauma score (PTS) were 7.41, 7.61 and 9.50 respectively and were statistically significantly associated with both LOS and morbidity $(\mathrm{P}<$ 0.05). All the patients had chest radiographs done; the commonest abnormal findings were hemothorax 32 (21.3\%) and rib fractures 31(20.7\%). Radiographs of limbs were done in 40 patients $(26.7 \%)$ and detected fractures in 27 patients (18.0\%). Abdominal ultrasound was done in eight patients and abnormal findings were detected in 3 patients (splenic rupture in 2 patients and haemoperitoneum alone in one patient). CT scan of the skull and brain was done in 31 patients $(20.7 \%)$ and detected abnormality in 23 patients (15.3\%) mainly brain edema in 14 patients (9.3\%), skull fractures in 11 patients ( 7.3\%) and space occupying lesions (epidural, subdural, subarachnoid and intra-cerebral hematoma) in 8 patients (5.3\%). Out of 150 patients, 83 patients $(55.3 \%)$ were treated by non-operative approach with

Table 3 Type of injuries

\begin{tabular}{lll}
\hline Types of injury & $\begin{array}{l}\text { Number of } \\
\text { patients }\end{array}$ & Percentages \\
\hline Chest wall wounds & 45 & 30.0 \\
Rib fractures & 31 & 20.7 \\
Flail chest & 1 & 0.7 \\
Clavicular fractures & 4 & 2.7 \\
Scapular fractures & 7 & 4.7 \\
Thoracic spine injury & 18 & 12.0 \\
Haemothorax & 32 & 21.3 \\
Pneumothorax & 2 & 1.3 \\
Pneumoheamothorax & 11 & 7.3 \\
Lung laceration & 1 & 0.7 \\
Hemopericardium & 1 & 0.7 \\
Esophageal injury & 1 & 0.7 \\
Acute Respiratory Distress & 3 & 2.0 \\
Syndrome & & \\
\hline
\end{tabular}


Table 4 Distribution of study population according to associated injuries

\begin{tabular}{lll}
\hline Associated injuries & Number of patients & Percentage \\
\hline Head/neck injuries & 50 & 33.3 \\
Abdominal injuries & 8 & 5.3 \\
Pelvic injuries & 5 & 3.3 \\
Musculoskeletal injuries & 40 & 26.7 \\
Multiple injuries & 1 & 0.7 \\
\hline
\end{tabular}

analgesics, antibiotics and tetanus prophylaxis. Underwater seal drainage was performed in 29 patients (19.3\%) in patients who had hemothorax, pneumothorax and haemopneumothorax and the average duration of drainage was 8.4 days. One patient $(0.7 \%)$ underwent thoracotomy due to hemopericardium. Surgical treatment for associated injuries is shown in table 5 .

Thirteen patients $(8.7 \%)$ were admitted in the ICU. The mean LOS in the ICU was 7.34 days.

The need for ICU admission was found to be significantly associated with mortality $(\mathrm{P}=0.021)$ Thirty nine patients $(26.0 \%)$ had complications. (Table 6).

The presence of complications was found to be significantly associated with mortality $(\mathrm{P}=0.001)$ but not with LOS $(\mathrm{P}=0.067)$

\section{Outcome of treatment}

The overall length of hospital stay ranged from 1 day to 120 days (mean $=13.17$ days). The LOS for non-survivors ranged from 1 day to 14 days (mean $=4.43$ days). Table 7 shows multivariate logistic regression analysis for LOS.

In this study, seven patients died giving a mortality rate of $4.7 \%$.Table 8 shows multivariate logistic regression analysis for mortality.

\section{Discussion}

In this study, most of our patients were youth in their most productive years and showed a male preponderance. Similar demographic observation was also reported by other authors $[8,9,15,16]$. The reason for male predominance among chest injury patients in this age group

Table 5 Treatment modalities of the associated injuries

\begin{tabular}{lll}
\hline Treatment modality & Frequency & Percentage \\
\hline Wound debridement & 44 & 29.3 \\
Closed reduction of factures & 23 & 15.3 \\
Open Reduction \& Internal Fixation (ORIF) & 6 & 4.0 \\
Exploratory laparotomy & 3 & 2.0 \\
- Spleenectomy & 2 & \\
- Repair of perforated bowels & 1 & \\
& & \\
Craniotomy + burr holes & 12 & 8.0 \\
Skull fracture elevation & 3 & 2.0
\end{tabular}

Table 6 Distribution of study population according to complications

\begin{tabular}{lll}
\hline Complications & Frequency & Percentage \\
\hline Wound sepsis & 22 & 14.7 \\
Complications of fractures & 18 & 12.0 \\
Post concussion syndrome & 7 & 4.7 \\
Pneumonia & 5 & 3.3 \\
Intra-abdominal complications & 5 & 3.3 \\
Empyema thoracis & 4 & 2.7 \\
Neurological deficit & 4 & 2.7 \\
Acute respiratory distress syndrome & 1 & 0.7 \\
\hline
\end{tabular}

is probably that males are more mobile with active participation in high risk taking activities. Identification of risk taking behavior among trauma patients has potential significance for the prevention of injuries.

The presence of pre-morbid illness has been reported to have an effect on the outcome of chest trauma patients $[17,18]$. In this study, pre-morbid illness was found to be significantly associated with mortality but not LOS.

Knowing the time of injury in trauma patient is important for prevention strategies and has an impact on the outcome. We noted that the majority of patients who arrived during night hours had poor prognosis compared to day arrivals. This can be explained by the fact that during night hours the majority of the senior surgical and auxiliary staff, whom we found to be pivotal in the diagnosis and management of chest injuries, were unlikely to be present unless called for difficult cases. In our resource-limited setting, where staff shortage is a challenging problem, re-distribution of the few staff available needs to be designed to address the problem.

Despite the fact that timing of medical care did not significantly affect the outcome of our patients in term of LOS and mortality, the author of the present study still believe that delay in seeking medical care still contributes significantly to high morbidity and mortality among chest injury patients. Early recognition and treatment of these injuries appear to reduce mortality and morbidity associated with the disease.

Most patients in this study sustained blunt chest injuries, which is comparable with other studies [19-21] but

Table 7 Multivariate logistics regression analysis for LOS

\begin{tabular}{llll}
\hline Independent variable & Odds ratio & $\begin{array}{l}\text { 95\% Confidence } \\
\text { Interval }\end{array}$ & p-value \\
\hline Associated injuries & 5.6 & $1.3-94.8$ & 0.003 \\
The type of injury & 13.6 & $3.3-24.3$ & 0.001 \\
Injury Severity Score & 2.6 & $0.9-8.7$ & 0.010 \\
Revised Trauma Score & 12.3 & $5.6-28.7$ & 0.001 \\
Pediatric Trauma Score & 11.2 & $4.2-23.8$ & 0.012 \\
\hline
\end{tabular}




\begin{tabular}{|c|c|c|c|}
\hline Independent variable & Odds ratio & $\begin{array}{l}\text { 95\% Confidence } \\
\text { Interval }\end{array}$ & $p$-value \\
\hline Pre-morbid illness & 2.3 & $1.2-97.1$ & 0.000 \\
\hline Associated injuries & 15.1 & $7.5-20.9$ & 0.001 \\
\hline The need for ICU admission & 13.9 & $8.2-67.1$ & 0.013 \\
\hline Injury Severity Score & 6.6 & $1.9-8.9$ & 0.020 \\
\hline Revised Trauma Score & 17.3 & $5.2-26.7$ & 0.011 \\
\hline Paediatric Trauma Score & 15.2 & $4.2-43.6$ & 0.015 \\
\hline Presence of complications & 12.9 & $6.8-34.1$ & 0.000 \\
\hline
\end{tabular}

in contrast with a Nigerian study [15] in which penetrating chest injuries was the most common mechanism of injury. The high incidence of blunt chest injuries in this study is explained by the fact that those patients who had blunt injuries were mostly involved in road traffic crush another common feature of increased motorization in this environment.

Road traffic crush (RTC) remains a leading cause of trauma and admissions to the accidents and emergency units of most hospitals in Tanzania and contributing significantly to high morbidity and mortality [22]. In this study, RTCs were the most common cause of injuries and the majority of these were due to motorcycle accidents, an emerging popular mode of commercial transportation in Mwanza City, and the victims were passengers, cyclists and pedestrians. Findings from this study calls for urgent interventions targeting at reducing the occurrence of RTCs and subsequently reduce the incidence of these injuries in this region.

The management of patients with chest injuries has several important elements: adequate pre-hospital care, rapid transport to a specialized centre, complex in-hospital care and rehabilitation. The prehospital phase plays a vital role in determining the final outcome of treatment when done appropriately and contributes significantly to reducing morbidity and mortality [23]. In the present study, prehospital treatment was reported in only $21.3 \%$ of chest injury patients which is in agreement with a study that was done in Ethiopia [15]. Lack of advanced pre-hospital care in Mwanza city is the major challenge in providing care for trauma patients and have contributed significantly to poor outcome of these patients due to delay in definitive management.

The type of injuries in this study is comparable with what is reported in other studies in Nigeria $[15,24]$ and Ethiopia [16]. In the present study, the type of injury significantly affected the LOS but not mortality. This finding reflects the low mortality rate among chest injury patients in this study.
The pattern of associated extra-thoracic injuries in this study is in agreement with findings from other studies done elsewhere $[15,25,26]$. The presence of associated injuries is an important determinant of the outcome of chest injury patients. Associated injuries increase the risk of complications in patients with chest injuries. Early recognition and treatment of associated extrathoracic injuries is important in order to reduce mortality and morbidity associated with chest injuries [21].

In our study, all the patients had chest radiographs done. This is in agreement with other studies done elsewhere $[15,16]$. Ultrasound of the chest has been reported to be an important diagnostic tool in the diagnosis of haemopneumothorax, in patients where $\mathrm{x}$-rays are not possible, as in unconscious patients and having pelvis or spine injury. Moreover, ultrasound also helps in differentiating between hemothorax and pulmonary contusion [27]. Atri et al [28] highlighted that ultrasound chest had a sensitivity of $94.6 \%$ for detecting pulmonary contusions and it was more sensitive than CT scan of the chest. However early thoracic CT scan has been very important in detecting injuries missed out by chest $\mathrm{x}$-ray. Neither ultrasound nor CT scan of the chest was done in our study.

The majority of our patients were managed by nonoperative approach which is in agreement with other studies [16,29-37]. This study has demonstrated that the majority of patients presenting with chest injury without associated injuries can be managed with procedures which can be readily performed in rural hospitals by well trained junior surgeons or experienced general practitioners using simple equipment such as chest tubes and underwater seal bottles. Thoracic surgeons generally agree that most patients with especially penetrating chest injuries could be managed adequately by closed thoracostomy tube drainage alone. Inci et al [8] reported the percentage to be between $62.1 \%$ and $91.4 \%$. Close monitoring of the bluntly injured patient is of paramount with repeated examination, radiographs, aortography, electrocardiogram, and CT scan of the chest and blood gas analysis as appropriate to detect changes.

The presence of complications has an impact on the final outcome of patients presenting with chest injuries. The pattern of complications in the present study is similar to what was reported in Nigeria by Ali et al [15]. Early recognition and management of complications following chest injury is of paramount in reducing the morbidity and mortality resulting from chest injuries.

The overall mean LOS in this study was higher compared to that reported by Atri et al [28] in India, but lower than that reported in the Nigerian study [15]. Non-survivors in the present study were found to have a shorter mean LOS and majority of deaths occurred during the first 24 hours of admission. The long period 
of hospital stay in our study was noted in patients with penetrating chest injuries and those with associated head injuries and long bone fractures. The length of hospital stay is an important measure of morbidity. Estimates of length of hospital stay are important for financial reasons, and accurate early estimates facilitate better financial planning by the payers. The overall mortality rate in this study was $4.7 \%$ comparable to that found in Nigeria [15], but relatively lower than that reported in other studies $[16,20,28,37]$. The reason for low mortality rate in the present study is that most of the patients were not severely injured except when there was a major associated extra-thoracic injury. They responded favorably to measures that were well within the competence of general surgeons and registrars. Limited study period and unavailability of thoracostomy tubes were the major limitation in this study.

\section{Conclusions}

Chest trauma is an important public health problem accounting for a substantial proportion of all trauma admissions at Bugando Medical Centre. The pattern of chest trauma and its management was almost similar to many series. RTC continues to be the major etiological factor for chest injuries and the commonly affected victims are young adult males in their productive and reproductive age group. Urgent preventive measures targeting at reducing the occurrence of RTCs is necessary to reduce the incidence of chest injuries in this region.

\section{Acknowledgements \\ We thank our patients, research assistants and staff members at the A \& E department, ICU, operating theatre and surgical wards for their support.}

\section{Authors' contributions \\ MKL contributed in study design, literature search, data analysis, manuscript writing \& editing. PLC participated in study design, data analysis, manuscript writing \& editing. JBM participated in data analysis, manuscript writing \& editing. WM supervised the study and contributed in data analysis, manuscript writing \& editing. All the authors read and approved the final manuscript.}

\section{Competing interests}

The authors declare they have no competing interest.

Received: 13 August 2010 Accepted: 18 January 2011 Published: 18 January 2011

\section{References}

1. Park K: Accidents. In Textbook of Social and Preventive Medicine. 17 edition. Edited by: Park K. Jabalpur: Banarsidas Co; 2000:304-5.

2. Wisner D: Trauma to chest. Sabiston and Spencer B Saunders publication; $61995,456$.

3. Miller DL, Mansour KA: Blunt traumatic chest injuries. Thoracic Surgery Clinics 2007, 17:57-61.

4. Taché S, Mbembati N, Marshall N, Tendick F, Mkony C, O'Sullivan P: Addressing gaps in surgical skills training by means of low-cost simulation at Muhimbili University in Tanzania. Human Resources for Health 2009, 7, 64

5. Bugando Medical Centre. Medical record database, 2008-2009.
6. Archampong EQ, Anyawu CH, Ohaegbulum SC: Management of the injured patient. In Principles and practice of surgery, including pathology in the tropics. Badoe EA, Archampong EQ. Edited by: Jaja MO. Ghana Publishing Company, Tema; 1994:139-143.

7. Frimpong-Boateng K, Amoati ABG: Chest injuries in Ghana. West Afr J Med 2000, 19:175.

8. Inci I, Ozçelik I, Tacyildiz O, Nizam N, Eren G, Ozen DB: Penetrating chest injuries: unusually high incidence of high velocity gunshot wounds in civilian practice. World J Surg 1998, 22:438-442.

9. Cooper C, Militello P: The multiple injured patient: Maryland shock trauma protocol approach. Thoracic Cardiovasc Surg 1992, 4:163.

10. Chalkiadakis G, Drositis J, Kafetzakis A, Kassotakis G, Mihalakis J, Sanidas E, Tsiftsis D, Valassiadou K: Management of simple thoracic Injuries at a level I trauma centre: can primary health care system take over? Injury 2000, 31:669-675.

11. Bender JS, Freedland M, Levison MA, Wilson RF: The management of flail chest injury: factors affecting outcome. J Trauma 1990, 30:1460-1462.

12. Catoire P, Orliaguet G, Liu N: Systemic transesophageal echocardiography for detection of mediastinal lesions in patients with multiple injuries. J. Trauma 1995, 38:96-102.

13. Grimes OF: Non penetrating injuries to the chest wall and esophagus. Surg Clin North Am 1972, 53:597-609.

14. Avakan S, Bishop M, Shoemaker WC: Evaluation of comprehensive algorithm for blunt and penetrating thoracic and abdominal trauma. American journal of surgery 1991, 57:737-46.

15. Ali N, Gali BM: Pattern and management of chest injuries in Maiduguri, Nigeria. Annals of African Medicine 2004, 3:181-184.

16. Adem AA, R llagoa R, Mekonen E: Chest injuries in Tikur Anbessa Hospital, Addis Ababa, Ethiopia: 3-year experience. East and Central African Journal of Surgery 2009, 6:11-14.

17. Shorr RM, Crittenden M, Indeck M, Hartunian SL, Rodriguez A: Blunt thoracic trauma: analysis of 515 patients. Ann Surg 1987, 206:200-205.

18. Otieno T, Woodsfield J, Bird P, Hill A: Trauma in rural Kenya. Injury 2004, 35:1228-1233.

19. Blasco E, Borro JM, Caffarena JM Jr, Galan G, Garcia-Zarza A, Padilla J, Paris E, Pastor J, Peiialver JC, Tarrazona V: Blunt chest injuries in 1696 patients. Eur J Cardio-thorac. Surg 1992, 6:284-287.

20. Kuzuku A, Liman ST, Ulasan GN, Tastepe Al, Topai S: Chest injury due to blunt trauma. European Journal of Cardiothoracic surgery 2003, 23:374-378.

21. William F, Anita L, Charlene M: Injury to the chest, complications and management: experience at a Level I trauma centre. Am. Journal of Surgery 1996, 1-6.

22. Museru LM, Leshabari MT: Road traffic Accidents in Tanzania: A 10-year epidemiological Appraisal. East Central Afr. J. Surg 2002, 7:23-26.

23. Aylwin CJ, Brohi K, Davies GD, Walsh MS: Pre-hospital and in-Hospital Thoracostomy:Indications and Complications. Ann R Coll Surg Engl 2008, 90:54-57.

24. Grover LG, Harman PK, Robinson PD, Trinkle JK: Management of penetrating lung injury in 184 Chest injuries in Maiduguri, Nigeria. Civilian practice. J Thorac Cardiovasc Surg 1995, 184.

25. Kalliopi A, Michalis G, Nikolaos T: Management of 150 flail chest injuries: analysis of risk factors affecting outcome. Eur J Cardiothorac Surg 2004, 26:373-376.

26. Inci I: Unusual high incidence of high velocity gunshot wounds in civilian practice. World Journal of Surgery 1998, 22:438-442.

27. Dulchavsky SA, Hamilton DR, Diebel LN, Sargsyan AE, Billica RD, Williams DR: Thoracic ultrasound diagnosis of pneumothorax. J Trauma 1999, 47:970-71.

28. Atri $\mathrm{M}$, Gurjit $\mathrm{S}$, Arvind $\mathrm{K}$ : Chest trauma in Jammu region an institutional study. IJTCVS 2006, 22:219-222.

29. Harrison WH, Gray AR, Couves CM, Howard JM: Severe nonpenetrating injuries to the chest. Clinical results in the management of 216 patients. Am J Surg 1960, 100:715-22.

30. Ozgen G, Duygulu I, Solak H: Chest injuries in civilian life and their treatment. Chest 1984, 85:89-92.

31. Kimberly KN, Roxanne RR, Robert FS, Kimberly TJ, Gary CA, Faran B, John B: Trans -mediastinal Gun shot wounds: Are Stable Patients really stable? World J. Surgery 2002, 26:1247-1250.

32. Raul C, Juan R, Marta L, Santiago Z, Rogelio C, Luis A, Pere S: Emergency treatment of sports injuries: An epidemiologic study. Emergencies 2009, 21:5-11. 
33. Bishop M, Shoemaker WC, Avakian S: Evaluation of a comprehensive algorithm for blunt and penetrating thoracic and abdominal trauma. American J Surg 1991, 57:737-46.

34. Gizaw T, Gebru W: Treatment of penetrating wound of chest. Ethiop Med J 1980, 18:81-9.

35. Lambrecth R, Nikodemos T: Penetrating chest injuries. Ethiopian Med J 1989, 27:223-27.

36. Inci I, Ozçelik I, Tacyildiz O, Nizam N, Eren G, Ozen DB: Penetrating chest injuries: unusually high incidence of high velocity gunshot wounds in civilian practice. World J Surg 1998, 22:438-442.

37. Massaga FA, Mchembe M: The Pattern and Management of Chest trauma at Muhimbili National Hospital, Dar es Salaam. East and Central African Journal of Surgery 2010, 15:124-29.

doi:10.1186/1749-8090-6-7

Cite this article as: Lema et al:: Pattern and outcome of chest injuries at Bugando Medical Centre in Northwestern Tanzania. Journal of Cardiothoracic Surgery 2011 6:7.

\section{Submit your next manuscript to BioMed Central} and take full advantage of:

- Convenient online submission

- Thorough peer review

- No space constraints or color figure charges

- Immediate publication on acceptance

- Inclusion in PubMed, CAS, Scopus and Google Scholar

- Research which is freely available for redistribution

Submit your manuscript at www.biomedcentral.com/submit
C Biomed Central 